\title{
ET UTVALG PUBLIKASJONER OM AFRIKA, UTVIKLINGSSTUDIER, NORD/SøR, DEN TREDJE VERDEN OG GLOBALHISTORIE
}

1. (1966). Organisasjonen for Afrikansk Enhet (OAU) i 1965. Etterord i C. Legum, Panafrikanismen (s. 174-187). Oslo: PAX.

2. (1967). Den afrikanske eliten og arven frå kolonitida. Syn og Segn, 10, 1-8.

3. (1967). Internasjonal handelspolitikk og de rike lands investeringer. I Det norske studentersamfunn. Dikt og Sak (s. 176-208). Oslo: Universitetsforlaget.

4. (1967). Utviklingshjelp: handelspolitikk eller almisser? Kirke og kultur, 8, 456-76.

5. (Red.). (1968). Afrika 1968. 4 artikler med diskusjonsopplegg. Oslo: Norske Skolers Afrikakomité.

6. (Red.). (1969). Afrika sør for Sahara. Oslo: Gyldendal.

7. (1969). Etterord. I Lucy Mair. Det nye Afrika (s. 197-217).

Oslo: Gyldendal.

8. (1970). FRELIMOs program for utvikling. Samtiden, 8, 497-509.

9. (1970). FN og stormaktsspillet. Tidens Ekko nr. 1, 1970-71. Oslo: NUPI. (24 s.) 
10. (Red.). (1970). Hva er USA-imperialismen? Oslo: Gyldendal.

11. (1970). USA i Afrika. I T. L. Eriksen (Red.), Hva er USA-imperialismen? (s. 65-81). Oslo: Gyldendal.

12. (1970). Eduardo Mondlane, FRELIMO og Norge. Forord i E. Mondlane, Kampen om Mocambique (s. 7-12). Oslo: Gyldendal.

13. (1970). Franz Fanon og jordens fordømte. I Yngvar Ustvedt (Red.). Stemmer fra den tredje verden (s. 27-43). Oslo: Gyldendal.

14. (1970). Sør-afrikanere i eksil. I Yngvar Ustvedt (Red.). Stemmer fra den tredje verden (s. 88-103). Oslo: Gyldendal.

15. (1972). Etterord. I L. Huberman og P. Sweezy. Sosialisme på Cuba. En studie av den økonomiske og politiske utviklingen etter revolusjonen (s. 197-203). Oslo: Gyldendal.16. (1972). Tanzania: fattige bønder og radikal politikk. Vår samtid, 8, 235-240.

17. (1973). Amilcar Cabral og Guinea-Bissau. En frigjøringsleder og en utviklingsmodell. Kirke og kultur, 2, 86-98.

18. (1973). U-land, u-hjelp og Norge. I Underutvikling og frigjøring (s. 12-21). Oslo: SFs studieforbund.

19. (1973). Afrika. Geografi for ungdomsskolen. Oslo: Gyldendal. (158 s.)

20 1973). Europa har underutvikla Afrika. Syn og Segn, 8. (Presentasjon av og intervju med Walter Rodney.) Også publisert på dansk i S. Christensen og A. F. Larsen (Red.). (1974). Det lænkede Afrika (s. 9- 18). København: SOC.

21. (1974). "A planlegge er a velge". Økonomiske og politiske endringer som bakgrunn for Tanzanias andre femårsplan. Universitetet i Trondheim: Hovedoppgave i historie. (351 s.)

22. (1974). (Red.). Underutvikling. En antologi om u-land og underutvikling i historisk perspektiv. (Utvalg, innledning, oversettelse av enkelte kapitler og kommentert bibliografi). Oslo: Gyldendal. (276 s.).

(Nytt opplag 1978).

23. (1974). Tanzania. Et av Norges samarbeidsland i Afrika. Oslo: NORAD. (40 s.)

24. (1974). Imperialismen og internasjonal politikk. Oslo: SFs studieforbund. (32 s.)

25. (1975). Zambia: Den vanskelige veien mot økonomisk uavhengighet. Internasjonal Politikk, 4, 557-74. 
26. (1975). Litteratur om Tanzania. Annoteret bibliografi. København: Mellemfolkeligt Samvirke. (90 s.)

27. (1975). Planlegging og samfunnsutvikling i Tanzania. I O. Stokke (Red.). Utviklingsplanlegging og samfunnsutvikling (s. 95-118). Oslo: NUPI. (Også publisert i Forum for utviklingsstudier, 7-8, 1974, 8-30.)

28. (1976). Kopperprisernas betydelse för den ekonomiska utvecklingen i Zambia. Stockholm: SIDAs Utredningsbyrå,Resultatvärdering 29. (107s.). www.bistandsdebatten.se/..../koppzamb.pdf

29. (1976). Frigjøring i det sørlige Afrika. Kirke og kultur, 9, 537-47.30. (1976). Hva er apartheid? I Norge og kampen mot apartheid (s. 3-20). Oslo: Fellesrådet for det sørlige Afrika.

31. (Red.). (1976). Afrika - frigjøringskamp og utviklingsstrategi. Særnummer Internasjonal Politikk, 3B.

32. (1976). Fra Rhodesia til Zimbabwe. Internasjonal Politikk, 3B, 659-688.

33. (Red.). (1976). Julius Nyerere, Fattigdom og frigjering. Artiklar og talar. (Utval og innleiing, s. 7-22). Oslo: Samlaget.

34. (1977). Afrika. Geografi og historie for ungdomsskolen. 2. reviderte utgave. Oslo: Gyldendal. (150 s.)

35. (1977). Kenyas politiske økonomi. Noen trekk ved den historiske opprinnelse. Oslo: Ulandsseminarets skriftserie. (55 s.)

36. (1977). Norsk bistandspolitikk, staten og næringslivet. Internasjonal Politikk, 4, 711736.

37. (1977). Råvarer, produsentsammenslutninger og hindringer for utvikling: kopper som eksempel. Oslo: PRIO. (123 s.)

38. (1978). Ytre avhengighet og indre hindringer for utvikling. Oslo: U-landsseminarets skriftserie. (20 s.)

39. (1978). Zambia. Et av Norges samarbeidsland i Afrika. Oslo: NORAD.

40. (1978). Africa in Modern History - en kommentar til Basil Davidsons nyeste bok. Paper til Seminarium om Afrikansk historia i Norden, Uppsala, mai. (24 s.)

41. (1978). Tidsskrifter og løpende publikasjoner om det sørlige Afrika. Nytt fran Nordiske Afrikainstitutet, 1, 15-31. 
42. (1978). Sør-Afrika i brennpunktet. I Hva er apartheid? Oslo: Fellesrådet for det sørlige Afrika. (52 s.)

43. (Medforfatter) (1978). Ny økonomisk verdensordning. Oslo: Sosialistisk Opplysningsforbund. (204 s.)

44. (1978, mai). Tanzanias utenrikspolitikk. Notat. Uppsala: Nordiska Afrikainstituttet. (21 s.)

45. (1978, oktober). Tanzania: hva er en strategi for "self-reliance"? Notat. Uppsala: Nordiska Afrikainstitutet. (24 s.)

46. (1978). Råvarer og produsentsammenslutninger: kopper og Zambia som eksempel. Internasjonal Politikk, 4, 685-709.

47. (1979). Tanzania. Et av Norges samarbeidsland i Afrika. Oslo: NORAD, 2. reviderte utgave. (40 s.)

48. (1979). Modern African History: Some Historiographical Observations (Research Report No. 55). Uppsala: Scandinavian Institute of African Studies. (28 s.) Også publisert i Scandinavian Journal of History, 4, 75-97.

49. (1979). Litteratur om Afrika syd for Sahara. Annoteret bibliografi. København: Mellemfolkeligt Samvirke. (116 s.). Svensk utgave: (1979). Litteratur om Afrika söder om Sahara. Uppsala: Nordiska Afrikainstitutet.

50. (1979). André Gunder Frank og Samir Amin: en bibliografisk oversikt. I S. Amin og A.G. Frank. På vei mot 1984 (s. 183-91). Oslo: Gyldendal.

51. Med Mikkelsen, B. (1979). Politiske rettigheter og politisk makt i u-land. Samtiden, 1, 77-85.

52. (1979). Språkundervisningen og den tredje verden. Lingva, 1, 20-31.

53. (1979). Zambia. Avhengig råvareøkonomi og underutvikling. I Underutvikling eller frigjøring? (s. 48-57). Oslo: Sosialistisk Opplysningsforbund.

54. Med Gudim $\varnothing$. (1979, mai). Solid bakgrunn for egne meninger. Aftenpostens dekning av konflikten i Rhodesia (Zimbabwe) 1977-79. Paper til seminaret Massemediarapportering i Norden om konfrontationen i södra Afrika, Kungälv. (20 s.)

55. Med Mikkelsen, B. (1979). Afrika. En verdensdel $i$ kart, tall og figurer. Uppsala: Nordiska Afrikainstitutet. (102 s.). Også utgitt i dansk, svensk og finsk oversettelse 
56. (1980). Afrikaforskning i Norden - noen dokumentasjonsproblemer. I B. Jørgensen og V. Stendrup (Red.). U-landsdokumentation i Norden (s.13-19). Arhus: NVBF.

57. (1980). Afrika i stormaktsspillet. Vår Samtid, 6, 20-28.

58. (1980). Underudvikling og afhængighæd - et historisk tilbageblik. I E. Buch-Hansen (Red.). Afrika - kontinent i krise (s. 9-30). København: Mellemfolkeligt Samvirke.

59. (1980). Mocambique - fra national befrielseskamp til opbygning af socialisme. I E. Buch-Hansen (Red.). Afrika - kontinent i krise (s. 165-186). København: Mellemfolkeligt Samvirke.

60. (1980). Zimbabwe: hva nå? (NUPI-Notat nr. 206). Oslo: NUPI. (22 s.)

61. (1981). Namibia - perspektiver for befrielse og udvikling. Den Ny Verden, 4, 167-91.

62. (1981). Sydafrika i krise, Den Ny Verden, 4, 116-23.

63. (1981). Namibia - hindringer og muligheter for utvikling. Oslo: NUPI. (76 s.). (Også publisert i Forum for utviklingsstudier, 1-3, 1981, 4-76).

64. (1981). Råvarer, gruveselskaper og internasjonal politikk: Namibia som eksempel, Internasjonal Politikk, 2, 237-66.

65. (1981). Namibia - hva slags framtid? (NUPI-Notat nr. 233). Oslo: NUPI. (17 s.)

66. (1982). Sanksjoner, Sør-Afrika og Norge (NUPI-Notat nr. 239). Oslo: NUPI (27 s.)

67. (1982). Namibia. Kolonialisme, apartheid og frigjøringskamp i det sørlige Afrika. Oslo: Universitetsforlaget. (252 s.). (NUPI: Utenrikspolitiske skrifter, nr. 38.)

68. (1982). Namibia - en landanalys. Stockholm: SIDA. (98 s.)

69. (1983). Avkolonisering av afrikansk historie: et historiografisk riss. I N. J. Ringdal (Red.). Frontlinjer $i$ historiefaget (s. 118-136, 154-157). Oslo: Universitetsforlaget.

70. (1983). Mosambik i det sørlige Afrika: sør-afrikansk destabilisering og regionalt utviklingssamarbeid. I O. Stokke (Red.). Mosambik. Utvikling og frigjøring i SørAfrikas slagskygge (s. 40-58). Oslo: NUPI.

71. (1984). Østafrikansk historiografi eller: Edvard Bull ti år etter. I Historie nedenfra. Festskrift til Edvard Bull (s. 44-59). Oslo: Universitetsforlaget.

72. (1984). Kenya. Et av Norges samarbeidsland i Afrika. Oslo: NORAD. (44 s.) 
73. (1984). Namibia. The historical evolution of the colonial economy: some basic features. (Research Report). Lusaka: UNIN. (52 s.)

74. (1985). Fra underutvikling til krise - noen trekk ved Afrikas økonomiske situasjon i 1980-åra. Oslo: NUPI. (64 s.). (Også publisert i Forum for utviklingsstudier, 1-4, 1984, 1-64.)

75. With Moorsom, R. (1985). The political economy of Namibia. An annotated, critical bibliography. Uppsala: The Scandinavian Institute of African Studies/Lusaka: UNIN/Oslo: NUPI. (423 s.)

76. (1985). Det sørlige Afrika. I J. J. Holst og D. Heradstveit (Red.). Norsk utenrikspolitikk (s. 244-266). Oslo: TANO.77. (1985). Namibiana. A current list. Oslo: NUPI. (154 s.). (Presented to the Seminar on Namibian Bibliography and Documenta tion. UN Institute for Namibia, Lusaka, 19-22 November 1985.)

78. (1985). Møte med David Livingstone. Oslo: Gyldendal. (140 s.). (Gyldendals biografiserie for barn og ungdom.) Ny utgave: Gyldendal/Bokklubbens Barn, 1996.

79. (1985). Zambia. Den historiske arven og dagens krise. (Med en omfattende bibliografi.). Lusaka, $121 \mathrm{~s}$. (Bakgrunnsdokumentasjon for CMIs landstudie av Zambia).

80. (1986). Norge, sanksjoner og Sør-Afrika. I Norsk Utenrikspolitisk Arbok 1985 (s. 83 112). Oslo: NUPI.

81. Med Mikkelsen, B., Palmberg M. (1986). Afrika i kort og tal. Ny utgave. København: Mellemfolkeligt Samvirke. (105 s.). (2. utgave, 2. opplag, 1988). (Svensk utgave: Basfakta om Afrika. Uppsala: Nordiska Afrikainstitutet, 1986.)

82. (1986). Afrika i krise. Oslo: Kirkens Nødhjelp. (48 s.). 2. rev. utg. 1988. Svensk utgave: Afrika i kris. Stockholm: Framtid för Afrika/SIDA.

83. (1986). Den brutale naboen. Sør-Afrikas krig mot nabostatene. Oslo: Fellesrådet for det sørlige Afrika. (48 s.)

84. (1986). Historical overview. I UNIN (Red.). Namibia. Perspectives for national reconstruction and development (s. 23-56). Lusaka: UNIN.

85. (1986). Innstillinger og meldinger om norsk bistandspolitikk - hvilken innstilling har de, og hva gir de meldinger om? (NUPI-Notat 364). Oslo: NUPI. (20 s.)

86. (Red.). (1987). Den vanskelige bistanden. Noen trekk ved norsk utviklingshjelps historie. Norwegian Foreign Policy Studies, No. 59. Oslo: Universitetsforlaget.

(257 s.). Egne bidrag: Kap. 1, 7, 10, 13 og bibliografi. 
87. (1987). Tanzania. Et perspektiv på 25 års utvikling. Oslo: NUPI. (48 s.). (Også publisert i Forum for utviklingsstudier, 1-3, 1987, 1-47.

88. (1987). Sydafrikas krig mot nabostatene. København: Mellemfolkeligt Samvirke. (64 s.)

89. (1988). Namibia. En landanalys. (2. utvidet utgave). Stockholm: SIDA. (164 s.)

90. (1988). Introduksjon til Afrika-forskningen: En bibliografisk veiledning (NUPI-notat nr. 396). Oslo: NUPI (30 s.)

91. (1988). Tanzania: A bibliography; Tanzania: The historical heritage; Norsk bistand til Tanzania, 1962-87. Tre bakgrunnsnotater til landstudien. Bergen: Universitetet i Bergen/Senter for utviklingsstudier, Bergen. (tilsammen 75 s.)

92. (1988). Afrika: Mat, makt og muligheter. Oslo: FN-Sambandet. (36 s.)

93. Med Gustavsson, T. (1988). Nord-Sør; En bibliografi over norsk bistands- og ulandsdebatt. Oslo: Den europeiske Nord-Sør-kampanjen. (45 s.)

94. (1988). Zimbabwe - en reise i historien. I H. Notaker (Red.). Utenfor allfarvei - om fjerne reisemål (s. 99-118). Oslo: Cappelen.

95. (1988). Slutten på verdenshistorien. Samleanmeldelse av fire bind i Aschehougs og Cappelens verdenshistorie. Historisk Tidsskrift, 67(1), 59-68.

96. (1988). Ingen tårer. Vår framtid er lys. Nelson og Winnie Mandela i den sørafrikanske frigjøringskampen. Oslo: Gyldendal. (160 s.). (Oversettelse til dansk, København, Mellemfolkeligt Samvirke, 1989.)

97. (1988). Det regionale samarbeidet mellom det sørlige Afrika og Norden. Oslo: NUPI. (42 s.). (Også publisert i Forum for utviklingsstudier, 1-3, 1988, 1-43).

98. (1988). Diamanter varer ikke evigt; Landsforrædernes cirkus. Begge i F. GjeddeNielsen (Red.). Namibia. København: WUS. (Ca. 20 s.)

99. (1988). Norden yder overlevelsesbistand til det sydlige Afrika. I T. Kitaj (Red). Den tredje verden 1988-89 (s. 30-35). København: Mellemfolkeligt Samvirke.

100. (1989). The Norwegian model: some reflections on Norwegian socio-economic development in the 19th century. Notat til The World Bank (Upublisert). (36 s.)

101. (1989). Modern historia (s.57-63); Politik och ekonomi (s.65-72) og Södra Afrika (s.93-99) i K. Rylander (Red.) Att studera Afrika. En litteraturvägledning. Uppsala: Nordiska Afrikainstitutet. (Ny utgave: 1995). 
102. (1989). The historical heritage I: Land occupation, colonial economy and settler rule. The historical heritage II: Liberation struggle and constitutional constraints, Political developments since independence og Zimbabwe: A bibliography. Oslo: HIFAB International. (ca. 65 s.). Forkortet utgave er publisert i Zimbabwe. A country study and aid review. Oslo/Harare: HIFAB, 1989.

103. (1989). Namibia: frigjøring, selvstendighet og utvikling. Stockholm: Afrikagrupperna i Sverige. (25 s.)

104. (1989). Norge og den tredje verden etter 1945. Et historiografisk riss og en forskningsoversikt. Oslo: NUPI. (60 s.). (Også publisert i Forum for utviklingsstudier, $8-10,1988,5-56$.

105. (1989). Namibia: South African withdrawal and preparations for destabilization. Bulletin of Peace Proposals, 20(3), 295-307.

106. (1989). Namibia: Economic prospects and challenges. Oslo: NUPI, (22 s.). (Paper, Norwegian People's Aids's international conference on Namibia, Oslo 21-22. November 1989.)

107. (1989). The political economy of Namibia. New and enlarged edition. Norwegian Foreign Policy Studies, No. 69. Lusaka: UNIN/Uppsala: Nordiska Afrikainstitutet/Oslo: NUPI (370 s.).

108. (1989). EF og den tredje verden. I R. Berg (Red.). "---og atter nei" (s. 92-118). Oslo: Pax.

109. (1989). Den afrikanske krise og afrikansk samfunnsforskning. Forum for utviklingsstudier, 2, 239-245.

110. (1989). Namiba after independence. Konferansepaper. Seinere publisert i Nordic organisations in independent Namibia. Uppsala: Nordic Africa Institute. (20 s.)

111. (1990). Namibias vei til selvstendighet. Oslo: NUPI. (20 s.). (Utgitt som seminarrapport, Stockholm: SIDA).

112. (1990). Litteratur om det sørlige Afrika. Oslo: NUPI/NORAD. (178 s.). Svensk oversettelse: Litteratur om det södra Afrika. Uppsala: Nordiska Afrikainstitutet, 1990. (174 s.). Forkortet dansk oversettelse: Litteratur om det sydlige Afrika. København: Mellemfolkeligt Samvirke, 1989 (134 s.)

113. (1990). Afrikas krise. Finnes det alternativer til Verdensbankens diagnose og medisin? Norwegian Foreign Policy Studies, No. 72. Oslo: NUPI. (334 s.)

114. (1990). Afrikas krise, Verdensbanken og IMF. Forum for utviklingsstudier, 2, 301-308.

115. (1990). Literature on Namibia at NUPI. An inventory list. Oslo: NUPI. (324 s.) 
116. Med Ofstad, A. (1990). Bibliography on Mozambique and international aid. Bergen: CMI. (52 s.)

117. (1990). Mozambique. Norwegian assistance in a context of crisis. Bergen: CMI. (Medarbeider på studien og forfatter av kap. 1).

118. (1990). Namibia: Documentation, libraries and research. I Working group on information and documentation session at the 8th EADI general conference (s. 7-18). Bergen: CMI/DERAP.

119. (1990). The reconstruction and development of Namibia. Noen kommentarer til dokumenter utarbeidet til UNDP-konferansen i New York, juni 1990. Oslo: NUPI. (26 S.)

120. (1991). Glimt fra det selvstendige Namibia. I B. Brekke (Red.). Står apartheid for fall? (s. 171-187). Oslo: Cappelen.

121. (1991). Namibia. Situations- og perspektivanalyse. København: DANIDA. (52 s.)

122. (1991). Litteratur om Afrikas krise, Verdensbanken og strukturtilpasning. Nytt från Nordiska Afrikainstitutet, 20-24.

123. (1992). Globale fordelingsproblem. I N. Aarsæther (Red.). Samfunnsplanlegging (s. 331-374). Oslo: Kommunalforlaget.

124. (1992). Hvorfor blir det stadig flere fattige i Afrika? I S. Gjerdåker og A. Tostensen (Red.). Alltid fattige (s. 63-87). Oslo: Cappelen.

125. (1993). Norge og verden fra 1850 til 1940. Oslo: Gyldendal. (387 s.)

126. (1993). Norge og verden etter 1940. Oslo: Gyldendal. (350 s.)

127. (1994). Verdenshistorie fra 1850 til våre dager. (Russisk tittel). St. Petersburg: Philosophy Library of the World. (552 s.)

128. Med M. Nyborg (1994). En norsk innledning. I Bruce Rich. Med jorda i pant. Verdensbankens rolle i miljø- og utviklingskrisen (s. 9-19). Oslo: Alternativ Framtid/Universitetsforlaget.

129. (1994). Norge og EU mellom nord og sør: En kritisk gjennomgang. Prosjekt Alternativ Framtid, Rapport 7/94. Oslo: Alternativ Framtid. (64 s.)

130. (1994). Review of research undertaken by The council for the development of economic and social research institutes in Africa (CODESRIA) and The Southern Africa Political Economy Series Project (SAPES) (Section C: South Africa and Regional Integration). Stockholm: SAREC. (12 s.) 
131. (1994). EU, Norge og den tredje verden. Alternativ Framtid, 3, 29-44, 49-50.

132. Med Birkenes J., Larsen, J.T., Rønhaug E., Vatne K. (1994). Ressursperm i historie. Norge og verden fram til i dag. Oslo: Gyldendal. (Eget bidrag ca. 20 s.)

133. Med Thonstad, T. (1994). Bistand og handel med utviklingsland. I Norge og EU. Virkninger av medlemskap i Den europeiske union (s. 97-108). Oslo: Nei til EU.

134. (1994). Norge og den tredje verden som etterkrigshistorisk forskningsfelt. Bergen: LOS-Senteret. (45 s.)

135. (1995). Fattigdomsspiralen: Forskjellige forklaringer. I N. C. Stenseth mfl. (Red.). Afrika: Natur, samfunn og bistand (s. 443-461). Oslo: Ad Notam.

136. (1995). Afrikas krise, markedsøkonomi og demokrati: noen bidrag fra afrikanske samfunnsforskere. I Fellesrådets Afrikaårbok '95 (s. 25-32). Oslo/Durban: Fellesrådet/Gazette Book.

137. (1996). Den europeiske unionen, Loméavtalen og Afrika. En oversikt og en kommentert bibliografi (NUPI-Rapport nr. 202). Oslo: NUPI. (242 s.)

138. (1996). EU, Lomé och Afrika. En översikt. Uppsala: Nordiska Afrikainstitutet. (26 s.)

139. (1997). Afrika i markedsfundamentalismens tid. I Fellesrådets Afrikaårbok 96/97 (s. 19-30). Oslo/Durban: Fellesrådet/Gazette Books.

140. Med Birkenes, J. (1997). Vår felles fortid. Verden før 1850. Oslo: Gyldendal. (352 s. Eget bidrag ca. $140 \mathrm{s.}$ )

141. (1997). Vår felles fortid. Norge og verden 1850-1940. Oslo: Gyldendal. (352 s.)

142. (1997). Vår felles fortid. Norge og verden fra 1940 til i dag. Oslo: Gyldendal. (364 s.)

143. (1997). Den globale fattigdommen: Afrika som eksempel. I G. Tufteland (Red.). Natur, samfunn og miljø (s. 45-62). Oslo: Universitetsforlaget.

144. (1997). Globalt apartheid. I F. Gustavsen \& I. M. Torkildsen (Red). Markedets vidunderlige verden (s. 85-102). Bergen: John Grieg Forlag.

145. (1998). COWI Consult. Evaluering av informasjonsstøtten til RORGene. Oslo: CowiConsult/Utenriksdepartementet. (Eget bidrag: 80 s.).

146. (1999). Den lange frigjøringskampen. I Tomm Kristiansen \& Aud-Lise Norheim (Red.). Høvdingen (s.23-68). Oslo: Cappelen. 
147. (1999). Er det mulig med Nord/Sør-dialog? Foredrag ved Vennskap Nord/Sørs konferanse i Trondheim, September. (10 s.).

148. (Red.) (2000). Norway and the liberation of Southern Africa. Uppsala: Nordiska Afrikainstitutet. Egne bidrag:"Introductory note", s. 7-8; "Chapter 1: The origins of a special relationship: Norway and Southern Africa 1960-1975", s. 9-87; "Chapter 5: Fuelling the war machine", s. 193-210 (med Krokan, A. K.); "Chapter 10: An ambiguous champion", s. 373- 399; "Bibiliography". www.liberationafrica.se/publications/91-7106-447-8.pdf

149. (2001). Globalisering: Vinnere og tapere. I Y. Boutrue \& V. Velle (Red.). En annen verden er mulig (s. 87-107). Oslo: Oktober. Også i A. Nærstad (Red.). (2001). Globalisér kampen, globalisér håpet. En annen verden er mulig (s. 10-39). Oslo: Utviklingsfondet.

150. (2001). Nettinformasjon om globalisering, handel, storselskaper, gjeld og Verdensbanken. I A. Nærstad (Red.). Globalisér kampen. Globalisér håpet. En annen verden er mulig (s. 251-275). Oslo: Utviklingsfondet.

151. (2002). Nelson Mandela. Et liv i kamp mot undertrykking og rasisme. Oslo: Omnipax. (156 s.)

152. (2002). Globalisering: At mykje er uklårt, er inga hindring. I T. Vagstøl \& R. Ås (Red.). Internasjonalt studiehefte (s. 63-69). Oslo: Norsk Målungdom.

153. (2003). Afrikas krise og vårt ansvar. I Global.no (Red.). Globalt (s. 8-13). Oslo.

154. (2003). Global makt og global apartheid. I K. Andersen (Red.). Makt - lesestykker for framtida (s. 23-33). Oslo: Gyldendal.

155. (2004). Nettinformasjon om globalisering, internasjonal økonomi og kampen for global rettferdighet. Oslo: SEFIA/Høgskolen i Oslo. (59 s.)

156. (2004). Myten om det gode Europa. Syn og Segn, 3, 8-14.

157. (2004). Historie. I K. Rylander (Red.). Att studera Afrika. Vägar till källorna (s. 6079). Uppsala: Nordiska Afrikainstitutet.

158. (2004). Politikk og økonomi. I K. Rylander (Red.). Att studera Afrika. Vägar till källorna (s. 80-102). Uppsala: Nordiska Afrikainstitutet.

159. (2004). EU i den globale kapitalismen. I H. Rudd (Red.). EU vs. USA (s. 6-17). Oslo: Nei til EU.

160. (2004). Noen globalhistoriske hovedlinjer fram til ca. 1900. Oslo: SEFIA/Høgskolen i Oslo. (132 s.) 
161. (2004). Frihandel eller solidaritet? I H. Rudd (Red.). Motvekt til solidaritet (s. 22-29). Oslo: Nei til EU.

162. (2004). A fair globalization: Creating opportunities for all. Sammendrag og presentasjon av rapporten fra ILOs World Commission on the Social Dimension of Globalization. Oslo: LOs internasjonale avdeling. (42 s.)

163. (2006). The project" Liberation and democracy in Southern Africa" at the Nordic Africa Institute. A forward-looking assessment. Uppsala: The Nordic Africa Institute. (23 s.)

164. (2006). Globalisation: Myth, miracle, monster? I D. Banik (Red.). Poverty, politics and development. Interdisciplinary perspectives (s. 104-133). Bergen: Fagbokforlaget.

165. (2006). Globalt økonomisk apartheid? Ti spørsmål om globalisering. I M. E. Marsdal (Red.). Økonomisk apartheid- nyliberalismens verdensorden (s. 21-63). Oslo: Attac/Solidaritet forlag.

166. (2007). Det tjuende århundrets første folkemord. Namibia 1903-1908. Oslo: Unipub. (208 s.). (Utgått fra forlaget, pdf-fil kan fås fra forfatteren.)

167. (2007). Tidslinjer 1. Verden og Norge. Historie Vg2. Oslo: Aschehoug. (s. 84-117, 134-155, 204-247).

168. (2007). Nord/Sør-, utviklings- og miljøspørsmål: Litteratur og nettressurser. Oslo: Statistisk Sentralbyrå. (286 s.)

169. (2008). Tidslinjer. Verden og Norge. Historie Vg3 (s. 308-345, 368- 391, 432-445). Oslo: Aschehoug.

170. (2008). Utslettelsen av Hererofolket i Namibia 1903-1908. I B. Hagtvet (Red.). Folkemordenes svarte bok (s. 133-155). Oslo: Universitetsforlaget.

171. (2008). Bør vi isteden snakke om globalt apartheid? I Sosialistisk Venstreparti (Red.). Marked og styring - et debatthefte for Verden til venstre (s. 12-17). Oslo: SV.

172. (2009). Solidaritet med begrensninger: Norge og det sørlige Afrika. I E. Niemi \& C. Smith-Simonsen (Red.). Det hjemlige og det globale (s. 213-230). Festskrift til Randi Rønning Balsvik. Oslo: Akademisk Publisering.

173. (2009). Kolonialisme og folkemord: Riss av en globalhistorisk fagdebatt. Historisk Tidsskrift, 88(3), 399-428.

174. (2009). Globalhistoriske hovedlinjer. Fra de første mennesker til imperialismens tidsalder. Oslo: SEFIA/Høgskolen i Oslo. (208 s.) (Utvidet og revidert utgave av nr. 160). 
175. (2009). A luta continua: Om sekstienere og sekstiăttere. I B. Ofstad (Red.). Rettferd og politikk. Festskrift til Hilde Bojer (s. 250-263). Oslo: Emilia forlag.

176. (2010). Globalhistorie 1750-1900. En sammenvevd og delt verden. Oslo: Cappelen Akademiske Forlag. (505 s.)

177. (2010). Frantz Fanon: Frigjøringsdialektikk, humanisme og avkolonisering av filosofien. Filosofisk Supplement, 4, 34-44.

178. (2010). Afrikas historie. I M. Andersson og Å. L. Moberg (Red.). Att studera Afrika, Vägar till källorna (s. 69-104). Uppsala: Nordiska Afrikainstitutet.

På nett: http://www.nai.uu.se. Engelsk utgave fra samme nettsted 2011.

179. (2010). Afrikas historie. I M. Andersson og A. L. Moberg (Red.). Att studera Afrika, Vägar till källorna (s. 105-148). Uppsala: Nordiska Afrikainstitutet 2010. På nett: http://www.nai.uu.se. Engelsk utgave fra samme nettsted 2011.

180. (2011). Tidslinjer. Ettbindsutgave for vg2. og vg3. Oslo: Aschehoug. (Egne bidrag ca. 150 s.)

181. (2011). Om produksjonsmåter og tenkemåter. Agora, 1, 186-208.

182. (2011). Fra eurosentrisme til global dannelse. I B. Hagtvet \& G. Ognjenovic (Red.). Dannelse. Tenkning, modning, refleksjon (s. 536-555). Oslo: Dreyers forlag.

183. (2011). Globalhistoria - en början. Kommenterad genomgång av källor. Paper til konferanse: Upplysning om global historia, Stockholm 12. november.

184. (2012). Guide til globalhistorien. Et sted à starte. Oslo: Salongen, Nettsted for filosofi og idéhistorie. (12 s.). http://www.salongen.no/?p=2598

185. (2012). Det tyske folkemordet i Namibia - noen nye perspektiver, Etter Lemkin, 4(1), 13-22.

186. (2012). Fattig og rik i samme verden. Hva kan vi vite om fattigdom og ulikhet, hvor skal vi hente kunnskap fra hva skal vi tro på? Oslo: FN- sambandet. (195 s.)

http://www.rorg.no/Ressursguider/Fattigdom og ulikhet/index.html

187. (2012). Adivasier, maoister og Arundhati Roy. Et riss av en indisk diskusjon, Agora, 4, 5-32.

188. Med K.B. Feldberg (Red.) (2013). Utvikling. En innføring i utviklingsstudier, Oslo: Cappelen Damm. (330 s.). Egne bidrag: Kap. 1: Hva er utviklingsstudier?, kap. 2: Fortida er ikke som før: Globalhistorie og utviklingsstudier, kap. 3: Globalisering, global kapitalisme eller globalt apartheid? og kap. 4 (med Oddvar Smukkestad): Bistand og utvikling i et nytt landskap. (Til sammen ca. $90 \mathrm{s.)}$ 
189. Med Lånkan R. B. (2014). Fattig og rik i samme verden. Undervisningsopplegg for den videregående skole i samfunnsøkonomi og samfunnsfag. Oslo: Global Skole. http://globalskole.no/videregaende/samfunnsfag/fattig...1

190. (2014). Verden på nett. Nettressurser om Nord/sør-, utviklings- og miljøspørsmål. Oslo: Rorg-samarbeidet. (125 s.)

http://www.rorg.no/Ressursguider/Verden_p_nett/index.html

191. (2014). Kolonialisme og folkemord. Namibia som eksempel. I B. Hagtvet mfl. (Red.) Folkemordenes svarte bok. 2. utgave. (s. 95-109). Oslo: Universitetsforlaget.

192. (2014). Nelson Mandela. Historien om den sørafrikanske frigjøringskampen. Oslo: Fellesrådet for Afrika. (70 s.) http://www.afrika.no/Detailed/23984.html

193. (2014). Mandela: Frigjøringsbevegelsens mann, Samtiden, 1, 124-141.

194. (2014). Verden er ikke som før. Men er alt nytt?, Nytt Norsk Tidsskrift, 3, 314-318.

195. (2014). Verdens som pyramide. I Hvor hender det?, nr. 25/2014 (NUPI) www.nupi.no/Publikasjoner/Innsikt-og-kommentar.....Verden-som-en-pyramide

196. (2014). Imperier och imperialism. I Maria Sjöberg (Red.). En samtidig världshistoria (s. 661-676). Lund: Studentlitteratur.

197. (2015). Hvorfor lese Samir Amin? Et biografisk og bibliografisk riss. I S. Amin: Kapitalismen i vår tid (s. 11-38). Larvik: Forlaget Rødt. 


\section{Bøker om andre emner}

(Red.). (1966). Ung profil. Essays av norske gymnasiaster. Oslo: PAX. (Redaksjon og forord.)

Med Rudeng, E. (1966). Foreningshåndbok.. Oslo: PAX. (141 s.)

Med Røed-Larsen S., Rosland, Kjell G. (1966). Verneplikten i fare. Oslo: PAX, 1966.

(Red.). (1969). Det politiske universitet. En bok om studenter og makt. Oslo:

Gyldendal.

(1970). Rapport fra Rana. Oslo: Gyldendal. (135 s.)

\section{Hva er ikke med?}

Det er ikke tatt med bokmeldinger i aviser/tidsskrifter (i de siste åra særlig i Ny Tid o g Tidsskriftet Rødt!), avisartikler/kronikker, kortere magasinartikler eller arbeider publisert i leksika (i første rekke Familieboka, Store Norske Leksikon, PAX-leksikon og Norsk biografisk leksikon).

For ei mer fullstendig liste fram til 1995, se En foreløpig bibliografi 1965-1995, 350 titler. Oslo: Norsk Utenrikspolitisk Institutt, 1995. 